\title{
Acceptance and preference for inter- and intraspecies social contact in rats
}

\author{
DAVID F. HALL and BIBB LATANÉ \\ Ohio State University, Columbus, Ohio 43210
}

\begin{abstract}
Social attraction to stimulus rats or gerbils tethered in an open field in single stimulus (social acceptance) conditions was compared to the proportion of time spent in contact with each stimulus animal in a two-stimulus (preference) condition. Stimulus rats were both more accepted and preferred than gerbils, and a greater proportion of total contact time was given to rats in the two stimulus condition. The presence of either a stimulus rat or of a stimulus gerbil in the open field was found to have significant fear reducing properties for subject rats, but rats were more effective than gerbils. The results suggest that social contact is regulated but, as with food preferences, there is an affective element in social attraction in rats.
\end{abstract}

Social attraction in rats seems to depend on the amount of social contact in which they have been allowed to indulge in their home cage. Rats which have been totally deprived of social contact in the home cage are significantly more affiliative in the open field than rats which have been housed in groups of two or more (Cappell \& Latané, 1969; Latané, Cappell, \& Joy, 1970; Latané, Nesbitt, Eckman, \& Rodin, 1972; Latané, Poor, \& Sloan, 1972; Latané, Schneider, Waring, \& Zweigenhaft, 1971; Latané \& Walton, 1972; Sloan \& Latané, 1974; Walton \& Latané, 1972). Social deprivation effects follow a temporal pattern typical of drive-like, homeostatically regulated processes. In particular, the most recent level of social experience has the greatest weight in determining the level of social attraction, and the effects of satiation develop much more rapidly than the effects of deprivation (Latané, Nesbitt, Eckman, \& Rodin, 1972).

Rats thus appear to regulate the amount of time spent in contact-not too much and not too little. This has led Latané and Werner, (Note 1) to suggest the existence of a "sociostat" in rats, a mechanism sensitive to the amount of prior time in contact which leads the rat to alter his present time in contact to achieve an appropriate balance. Latané and Werner report average distances between rats tested in a large open field to be about three times that of rats tested in a small field, consistent with the fact that the diameter of the large field was three times that of the small. However, rats spent the same amount of time in contact in both fields, despite the fact that the area of the large field was nine times that of the small. And, as in previous studies, alone housed rats were more affiliative than paired housed rats. This suggests that time in contact was regulated, but not distance.

This research was supported by an Ohio State University Fellowship to D. H., by National Science Foundation Grants GS27340 and GS40194, and by a Guggenheim Fellowship to B. L. Request reprints from Bibb Latane, 404C West 17th Avenue, Columbus, Ohio 43210.
Although rats do seem to regulate the amount of time spent in social contact with other rats, they do not spend the same amount of time in contact with social partners of different species. Rats are attracted to such other creatures as gerbils, hamsters, and even a properly responsive human hand, spending more than a chance amount of time in contact with these lively interspecies social partners (Werner \& Latanë, 1974; Walton \& Latané, Note 2). But, they do not spend as much time with them as they do with other rats. For example, Walton and Latane (Note 2) found in four experiments that rats spent slightly less than half as much time in contact with gerbils as with rats. Why?

The most immediately obvious explanation is that these other species provide inadequate or inappropriate opportunities for satisfying interaction. Gerbils, hamsters, and rats differ in the temporal and topographical patterning of their behavior, and these differences might prevent the occurrence of mutually satisfying interaction. Responses of one species may simply not stimulate another in a sufficiently enjoyable or reinforcing way to motivate approach; and there may be something analogous to a communications barrier between species. This line of thought suggests that members of other species receive less acceptance than rats because they have less to offer than rats.

However, there is an opposite viewpoint. The fact that rats spend less time with gerbils does not necessarily mean that contact with gerbils is less satisfactory than intraspecies contact. It might simply mean that it takes less contact with a gerbil than with a rat to satisfy the rat's drive. It may be that gerbils with their higher rate of activity and greater novelty and unpredictability more quickly satiate the rat's need for gregarious interaction. This line of speculation is based on consideration of a caloric model of drive satiation.

Young and Greene (1953) gave rats the opportunity to drink sucrose solutions varying in concentration from $9 \%$ (diluted) to $36 \%$ (super sweet). When rats were given 
only one solution at a time, they imbibed more of the $9 \%$ than of $18 \%$ or of a $36 \%$ solution. However, when experimental conditions were altered so that animals had a choice, they showed a strong preference for the $36 \%$ solution. It appears subjects will take nourishment from whatever source is available in the single stimulus situation, drinking enough to satisfy caloric needs, but, given a choice, the subject prefers to take its nourishment from the sweeter source. It is possible that, in similar fashion, contact with gerbils might more quickly satisfy a rat's needs for social stimulation than contact with a rat. According to this view, rats spend less time with gerbils than with rats because gerbils are more satisfying, not less satisfactory, than rats.

The present experiment sought to test this alternative explanation for the apparent unattractiveness of gerbils to rats by allowing rats to choose between a rat and a gerbil as well as measuring the absolute time spent with either when no choice is possible. Thus, the design incorporates both "single bottle" tests, with rat or gerbil stimuli presented alone (as in Walton \& Latané, Note 2) and a new "double bottle" test in which both a rat and gerbil are available at the same time. If rats given a choice prefer social contact with a gerbil, then the inference would be that interspecies contact is somewhat sweeter and more quickly satisfying than contact with a rat. If, on the other hand, contact with a rat is preferred, then the inference would be that gerbils are an unpalatable social partner, possibly less satisfying, and definitely less attractive than a rat.

A second purpose of this study was to investigate the fear-reducing properties of rats and gerbils. Rats exposed alone to the open field typically defecate far more than rats tested in pairs (Latané, 1969; Latané \& Glass, 1968). Likewise rats tested with gerbils defecate significantly more than rats tested with rats (Walton \& Latané, Note 2). However, defecation in the presence of a gerbil has never been compared to an alone base rate and thus might represent either an increase above the base rate for rats tested alone or merely a lesser reduction from the base rate than is obtained with rats. If contact with gerbils results in a rate of defecation greater than the base rate for testing alone, it could be concluded that gerbils are emotionally arousing to rats, either because of heightened excitement from a stimulating social partner or negative affect resulting from contact from an unfamiliar animal. If, on the other hand, gerbils are merely less effective than rats in reducing emotionality, then the hypothesis that a gerbil is a minimally satisfying social partner would be supported.

\section{METHOD}

\section{Subjects and Apparatus}

Thirty-six male, naive Sprague-Dawley rats (Laboratory Supply Company, Indianapolis) were about 70 days old on arrival in our laboratory, and were housed singly in
$7 \times 10 \times 7$ in. cages for about 10 days with ad-lib food and water before testing in the open field. Six naive male rats and six male gerbils served as stimulus animals.

Subjects were observed in a circular open field, $4 \mathrm{ft}$. in diam with walls 18 in. high (Latané, 1969). The walls and floor of the field were painted glossy white with black markings, and the field was illuminated by a $40-\mathrm{W}$ bulb in a conical shield suspended $3 \mathrm{ft}$. above the floor.

\section{Procedure}

Subjects were tested in the open field $5 \mathrm{~min} /$ day for 8 consecutive days under four different conditions of access to tethered stimulus animals. In two conditions, a single stimulus rat or gerbil was tethered with a short string to a spot near the periphery of the open field. In a third condition, both a stimulus rat and a stimulus gerbil were tethered near the outer wall of the field, separated by $180 \mathrm{deg}$. In a final condition, the subject rat was run alone with no stimulus animal present. Subjects were tested twice each under each of these conditions in counterbalanced order.

The total time during which subjects maintained direct physical contact with each stimulus animal and the number of fecal boluses dropped by the subject were measured.

\section{RESULTS}

\section{Time in Contact}

Subject rats spent nearly half the time in the open field in contact with single rats (49\% time in contact). Time in contact with single gerbils was significantly less [21\% time in contact; $(\mathrm{F}=71.4 ; \mathrm{df}=1 / 32, \mathrm{p}<.001)]$. These results are similar to those obtained by Walton and Latané (Note 2). However, time in contact with gerbils was considerably more than would be expected by chance alone, indicating that rats were attracted, not indifferent or repelled, to gerbils.

When both a stimulus rat and a stimulus gerbil were in the open field, rats significantly reduced their time in contact with each species. Time spent with rats in the two stimulus condition was reduced to $39 \%(\mathrm{~F}=8.7$; df $=1 / 32 ; p<.01)$ and time with gerbils to $10 \%(F=42.7$; $\mathrm{df}=1 / 32 ; \mathrm{p}<.001)$. However, total time in contact with both stimulus animals was identical to time in contact with single rats (49\%). In other words, subjects' social attention was divided between two stimulus animals, but total contact time was equal to the time spent with a single stimulus rat.

In the single stimulus conditions, the average ratio of time in contact with rats to total time in contact with both stimulus animals was .67. In the two stimulus condition, with both a rat and a gerbil in the open field, this ratio was .74 , significantly greater $(F=5.29$; $\mathrm{df}=$ $1 / 32 ; p<.05)$. That is, subjects devoted a larger proportion of their total contact time to rats when allowed to choose between rats and gerbils. Thus, rats demonstrated a significant preference as well as greater acceptance for their own species.

\section{Defecation}

Stimulus rats and stimulus gerbils were both effective in reducing defecation [Table 1. Rats: $F(1,32)=31.9$, 
$\mathrm{p}<.001$. Gerbils: $F(1,32)=5.14, \mathrm{p}<.05)$. Single rats were significantly more effective than having no stimulus animal $(\mathrm{p}<.01)$, or than single gerbils $(\mathrm{p}<.01)$. Defecation in the presence of both stimulus animals did not differ from defecation in the presence of single rats. Thus, as in the case of attraction, gerbils are better than nothing, but not as good as rats.

\section{DISCUSSION}

The fact that total time in contact in the two stimulus condition was identical to time in contact with single rats suggests that contact with gerbils is functionally equivalent to contact with rats. This suggestion is supported by the fact that contact with rats and gerbils are both effective, if not equally effective, in reducing fear-related defecation. Gerbils seem to be partially, if not completely substitutable for rats.

Even though contact with gerbils had many of the same effects as contact with rats, rats not only spend more time with rats, but even preferentially discriminate in favor of them when given a choice. Gerbils differ from rats along many static stimulus dimensions, but it is probably even more important that gerbils and rats differ in the tempo and style of their behavior.

Latané and his colleagues (e.g., Latané \& Hothersall, 1972) have suggested that the major source of social attraction in rats is the opportunity for interaction. The attractiveness of a social partner is determined not by its static stimulus qualities, but by its stimulating responsiveness (Latané, Joy, Meltzer, Lubell, \& Cappell, 1972). Compatibly responsive animals can achieve mutually satisfying interaction, while incompatible response patterns make interaction difficult. Gerbils are frenetic, excitable and flighty, disinclined to stay in one spot long enough for extended interaction; rats are slower paced and more methodical about their social behavior. The differences between the responsive patterns of rats and gerbils appear to limit the amount of interest the two species will display toward each other.

To the extent that an organism eats or behaves toward an object to satisfy an internal need, there should be a negative relationship between acceptance (single bottle) and preference (double bottle) measures. When tested for acceptance, more of the less satisfying object must be consumed to satisfy the need, whereas when animals are allowed to exhibit a preference, they can satisfy their need more easily by choosing the more satisfying substance. The results of the present experiment suggest that there must be more to time in contact with gerbils or with rats than simple regulation of a homeostatic sociability drive.

Paul Thomas Young, reviewing research on food preferences in 1948, noted that some foods rank high both on acceptance and preference tests. For example, at an optimum solution concentration level, rats consume more sodium chloride (solvate) than at greater or lesser concentration levels. At this most acceptable and preferred level, rats actually consume a harmful amount of salt. Young concluded that animals eat or drink not only because they need to but because they like to. Acceptance and preference are determined in part by affective reactions to food and liquids.

Likewise, we think the present results suggest an affective element in social interaction. Rats were both more accepted than and preferred to gerbils, suggesting that rats like intraspecies contact better than interspecies contact. This result strengthens
Table 1

Defecation Per Trial as a Function of the Presence or Absence of Stimulus Animals

\begin{tabular}{lccc}
\hline & $\begin{array}{c}\text { Gerbil Not } \\
\text { Present }\end{array}$ & $\begin{array}{c}\text { Gerbil } \\
\text { Present }\end{array}$ & \\
\hline Rat not present & $3.29_{\mathrm{a}}$ & $2.33_{\mathrm{b}}$ & 2.81 \\
Rat present & $1.39_{\mathrm{c}}$ & $1.23_{\mathrm{c}}$ & 1.31 \\
& 2.34 & 1.78 & 2.06 \\
\hline
\end{tabular}

Note-Cell entries with different subscripts are significantly different at the .01 level by the Newman-Keuls criterion.

the suggestion that rats engage in social contact for the opportunity for mutually satisfying interaction. Social interaction seems to be a pleasant and exciting experience for rats.

\section{REFERENCE NOTE}

1. Latané, B., \& Werner, C. The regulation of social contact in rats: Time, not distance, Submitted for publication.

2. Walton, D., \& Latané, B. Social contact and social attraction among rats, gerbils, and hamsters. Submitted for publication.

\section{REFERENCES}

Cappell, H., \& Latané, B. Effects of alcohol and caffeine on the social and emotional behavior of the rat. Quarterly Journal of Studies on Alcohol, 1969, 30, 345-356.

Latané, B. Gregariousness and fear in laboratory rats. Journal of Experimental Social Psychology, 1969, 5, 61-69.

Latané, B., Cappell, H., \& Joy, V. Social deprivation, housing density, and gregariousness in rats. Journal of Comparative and, Physiological Psychology, 1970, 70, 221-227.

Latané, B., \& Glass, D. Social and nonsocial attraction in rats. Journal of Personality and Social Psychology, 1968, 9, 142-146,

Latané, B., \& Hothersall, D. Social attraction in animals. In Dodwell, P. C. (Ed.) New horizons in psychology II. Penguin Books, 1972 .

Latané, B., Joy, V., Meltzer, J., Lubell, B., \& Cappell, H. Stimulus determinants of social attraction in rats. Journal of Comparative and Physiological Psychology, 1972, 79, 13-21.

Latané, B., Nesbitt, B., Eckman, J., \& Rodin, J. Long- and short-term social deprivation and sociability in rats. Journal of Comparative and Physiological Psychology, 1972, 81, 69-75.

Latane, B., Poor, D., \& Sloan, L. Familiarity and attraction to social and nonsocial objects by rats. Psychonomic Science. 1972, 26, 171-172.

Latané, B. Schneider, E., Waring, P., \& Zweigenhaft, R. The specificity of social attraction in rats. Psychonomic Science, $1971,23,28-29$.

Latané, B., \& Walton, D. Effects of social deprivation and familiarity with the environment on social attraction in rats. Psychonomic Science, 1972, 27, 9-11.

Sloan, L. R., \& Latané, B. Social deprivation and stimulus satiation in the albino rat. Journal of Comparative and Physiological Psychology, 1974, 87, 1148-1156.

Walton, D., \& Latane, B. Visual versus phyaical social deprivation and affiliation in rats. Psychonomic Sclence, 1972, 26, 4-6.

Werner, C., \& Latane, B. Interaction motivates attraction: Rats are fond of fondling. Journal of Personality and Social Psychology, 1974, 29, 328-334.

Young, P. T. Appetite, palatibility, and feeding habit: A critical review. Psy chological Bulletin, 1948, 45, 289-320.

Young, P. T., \& Greene, J. T. Quantity of food ingested as a measure of relative acceptability. Journal of Comparative and Phy siological Psychology, 1953, 49, 288-294.

(Received for publication January 24, 1975.) 